University of Nebraska - Lincoln

DigitalCommons@University of Nebraska - Lincoln

\title{
$9-2011$
}

\section{Numerical Modeling of Steady Burning Characteristics of Spherical Ethanol Particles in a Spray Environment}

\author{
Vaibhav Kumar Sahu \\ IIT Madras, Chennai, India \\ Vasudevan Raghavan \\ IIT Madras, Chennai, India, raghavan@iitm.ac.in \\ Daniel N. Pope \\ University of Minnesota, Duluth, dpope@d.umn.edu \\ George Gogos \\ University of Nebraska-Lincoln, ggogos1@unl.edu
}

Follow this and additional works at: https://digitalcommons.unl.edu/mechengfacpub

Part of the Mechanical Engineering Commons

Sahu, Vaibhav Kumar; Raghavan, Vasudevan; Pope, Daniel N.; and Gogos, George, "Numerical Modeling of Steady Burning Characteristics of Spherical Ethanol Particles in a Spray Environment" (2011). Mechanical \& Materials Engineering Faculty Publications. 64.

https://digitalcommons.unl.edu/mechengfacpub/64

This Article is brought to you for free and open access by the Mechanical \& Materials Engineering, Department of at DigitalCommons@University of Nebraska - Lincoln. It has been accepted for inclusion in Mechanical \& Materials Engineering Faculty Publications by an authorized administrator of DigitalCommons@University of Nebraska Lincoln. 


\section{Numerical Modeling of Steady Burning Characteristics of Spherical Ethanol Particles in a Spray Environment}

\author{
Vaibhav Kumar Sahu \\ Graduate Student \\ Vasudevan Raghavan ${ }^{1}$ \\ Assistant Professor \\ e-mail: raghavan@iitm.ac.in \\ Department of Mechanical Engineering, \\ IIT Madras, \\ Chennai, India
}

\author{
Daniel N. Pope \\ Associate Professor \\ Department of Mechanical Engineering, \\ University of Minnesota, \\ Duluth, MN 55812
}

\author{
George Gogos \\ Professor \\ Department of Mechanical Engineering, \\ University of Nebraska, \\ Lincoln, NE 68588
}

A numerical study of steady burning of spherical ethanol particles in a spray environment is presented. A spray environment is modeled as a high temperature oxidizer stream where the major products of combustion such as carbon dioxide and water vapor will be present along with reduced amounts of oxygen and nitrogen. The numerical model, which employs variable thermophysical properties, a global single-step reaction mechanism, and an optically thin radiation model, has been first validated against published experimental results for quasi-steady combustion of spherical ethanol particles. The validated model has been employed to predict the burning behavior of the ethanol particle in high temperature modified oxidizer environment. Results show that based on the amount of oxygen present in the oxidizer the burning rate constant is affected. The ambient temperature affects the burning rate constant only after a sufficient decrease in the oxygen content occurs. In pure air stream, ambient temperature variation does not affect the evaporation constant. Results in terms of burning rates, maximum temperature around the particle, and the evaporation rate constants are presented for all the cases. The variation of normalized Damköhler number is also presented to show the cases where combustion or pure evaporation would occur. [DOI: 10.1115/1.4003905]

Keywords: ethanol, spray combustion, burning rate, evaporation rate constant, single-step reaction kinetics, optically thin radiation model

\section{Introduction}

Ethanol has become a promising renewable automotive fuel because of its easier production and availability, economic factors,

\footnotetext{
${ }^{1}$ Corresponding author.

Contributed by the Heat Transfer Division of ASME for publication in the Journal of Heat Transfer. Manuscript received January 14, 2011; final manuscript received March 25, 2011; published online August 1, 2011. Assoc. Editor: Giulio Lorenzini.
}

and combustion characteristics. It has also been considered as a low polluting liquid propellant for rocket propulsion application [1]. Combustion of any liquid fuel as particles or droplets occurs in several practical systems including internal combustion engines and liquid fuel fed industrial furnaces. Experiments for the burning of liquid fuel particles have been carried out in the past by several researchers [2-8]. Suspended droplets, free droplets, and liquid fuel fed through porous spheres have been studied. The mass burning rate, evaporation rate constant, and the extinction and emission characteristics have been studied thoroughly. Quasi-steady theoretical and numerical models to simulate steady droplet evaporation or combustion are applicable for the low pressure burning of fuel particles, after the initial ignition and internal heating transients are over. Such studies have been reported in the past by researchers [912]. Over the years, detailed kinetics studies on ethanol oxidation have also been reported [13-17]. These studies explain the basic oxidation characteristics and structure of ethanol flames. Recently, a single-step kinetics mechanism for ethanol-air oxidation, which can be used for modeling diffusion flames, has been reported by Dubey et al. [18]. Such mechanism can be used to model ethanol flames in larger combustion systems where the detailed mechanisms will be computationally expensive. Evaporation and combustion studies of liquid fuel particles in high temperature and air diluents environments have also been investigated by several researchers [19-24]. These studies show an increased rate of evaporation in high temperature ambient and reduced evaporation rates when oxygen in the oxidizer decreases. These are the possible effects for a liquid fuel particle burning in a spray environment.

From the brief literature presented above, it can be noted that studies on droplet burning in a spray environment, which typically has higher temperature and lower oxygen content in the oxidizer, has not been studied in detail, especially for new biofuel such as ethanol. These studies will help in understanding the effect of a spray ambient on the evaporation and burning behavior of liquid fuel particle under normal gravity. A spray environment is modeled as a high temperature stream flowing over the particle with modified oxidizer containing major products of combustion such as carbon dioxide and water vapor along with reduced amounts of oxygen and nitrogen. The numerical model, which employs variable thermophysical properties, a global single-step reaction mechanism, and optically thin radiation model, has been first validated against published experimental results available for quasi-steady combustion of spherical ethanol particles. The validated model has been employed to predict the burning behavior of the ethanol particle in high temperature modified oxidizer environment.

\section{Numerical Model}

A complex problem of combustion of a fuel particle in a mixed convective environment is simplified using the following assumptions:

(1) Two-dimensional, axisymmetric, and laminar flow.

(2) Particle is spherical and its diameter is constant as in porous sphere experiments (steady burning) [7] and mass consumption of fuel varies with changes in ambient conditions.

(3) Ideal-gas mixture formulation is used to account for density variations with temperature and concentration.

(4) Only the gas phase region has been modeled in a decoupled manner with no particle heating effects, assuming no slip condition for the tangential velocity component at the particle surface. These approximations are applicable to low pressure burning of a fuel particle, during the quasi-steady burning period.

(5) Single component fuel undergoing complete combustion through a global single-step reaction has been considered.

(6) The partial pressure of vapor adjacent to the particle surface is assumed to be equal to the vapor pressure of the fuel at the interface temperature. 


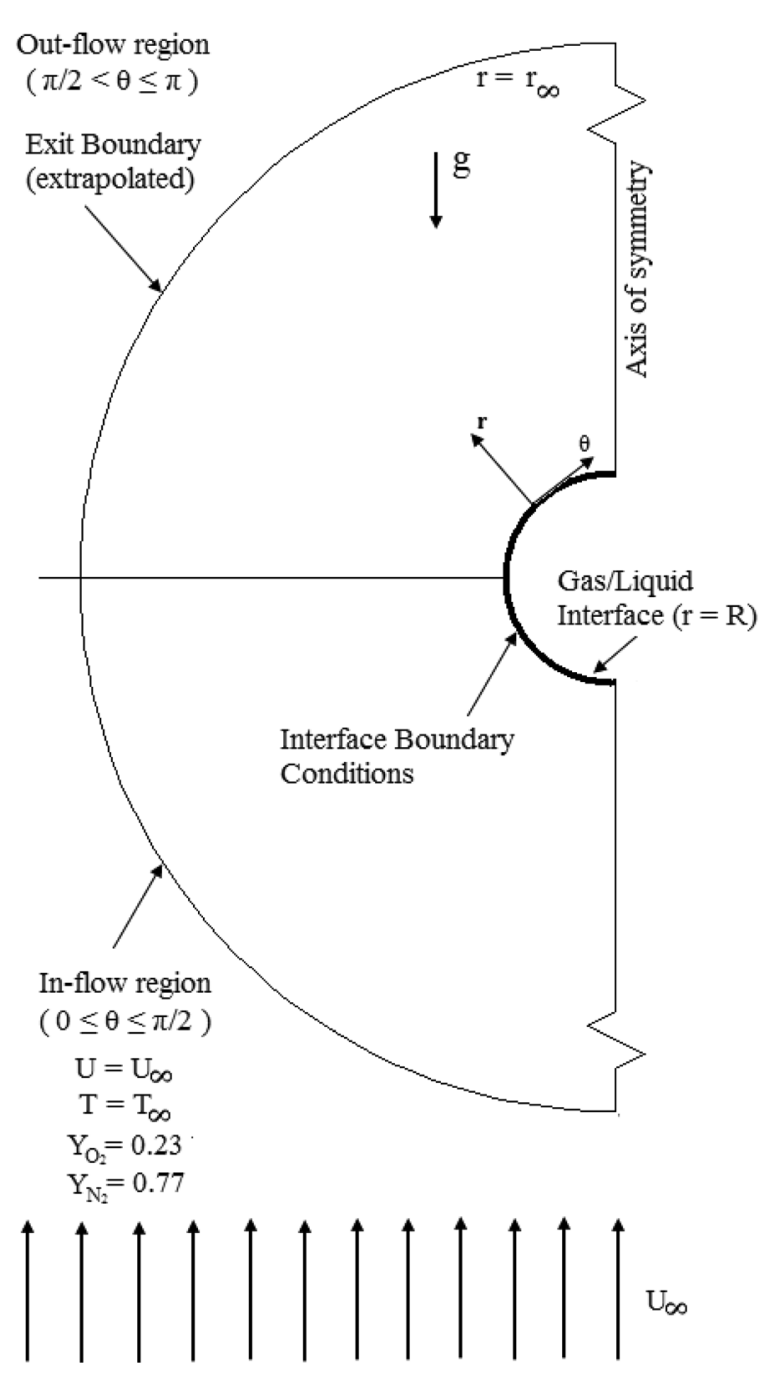

Fig. 1 Computational domain

(7) Radiation losses from the flame are modeled using an optically thin radiation model, where heat is absorbed by species such as carbon dioxide and water vapor.

The computational domain along with the boundary conditions is shown in Fig. 1. The free stream oxidizer flows from bottom to top and aids the buoyancy induced flow (gravity vector is in downward vertical direction). The domain is in polar spherical coordinate system with $r$ and $\theta$ as the radial and angular coordinates. The details of the governing equations, multicomponent diffusion formulation, implicit time marching solution procedure, and evaluation of variable thermophysical properties are available elsewhere [11]. The fuel has been changed to ethanol. Its thermophysical properties have been estimated as a function of temperature and species concentration.

The energy conservation equation, which has been modified in this work to account for nonluminous thermal radiation, is given by

$$
\begin{aligned}
\frac{\partial}{\partial t}(\rho T)+\nabla \cdot(\rho \mathbf{v} T)= & \nabla \cdot\left(\frac{k}{c_{p}} \nabla T\right)+\frac{k}{c_{p}^{2}} \nabla T \cdot \nabla c_{p}-\frac{1}{c_{p}} \sum_{i=1}^{N} \omega_{i} h_{i} \\
& -\frac{\rho}{c_{p}} \sum_{i=1}^{N} Y_{i} \mathbf{V}_{i} \cdot \nabla h_{i}+\frac{\dot{q}_{R}^{\prime \prime \prime}}{c_{p}}
\end{aligned}
$$

In Eq. (1), $T$ is the temperature, $k, c_{p}$, and $\rho$ are mixture thermal conductivity, specific heat, and density, respectively, and $\boldsymbol{V}_{\boldsymbol{i}}, \omega_{i}$, and $h_{i}$, are the diffusion velocity, net rate of production, and absolute enthalpy of $i$ th species, respectively. The numerator in the last term on the right hand side represents the radiative heat flux. The radiative heat flux is determined using the optically thin approximation [25], which is given by

$$
\dot{q}_{R}^{\prime \prime \prime}=-4 \kappa_{p} \sigma_{B}\left(T^{4}-T_{\infty}^{4}\right)
$$

where $\kappa_{p}$ is the total Planck-mean absorption coefficient and $\sigma_{B}$ is the Stefan-Boltzmann constant $\left(5.6697 \times 10^{-8} \mathrm{~W} / \mathrm{m}^{2} \mathrm{~K}^{4}\right)$. The total Planck-mean absorption coefficient has been calculated using the expression $\kappa_{p}=X_{\mathrm{CO}_{2}} \kappa_{p} \mathrm{CO}_{2}+X_{\mathrm{H}_{2} \mathrm{O}} \kappa_{p \mathrm{H}_{2} \mathrm{O}}$, where $X$ represents the mole fraction. The Planck-mean absorption coefficients for the species $\mathrm{CO}_{2}$ and $\mathrm{H}_{2} \mathrm{O}\left(\kappa_{p} \mathrm{CO}_{2}\right.$ and $\kappa_{p \mathrm{H}_{2} \mathrm{O}}$, respectively) have been evaluated using temperature polynomials [25].

The interfacial coupling equations consist of the following. The tangential velocities at the interface are set to zero $\left(v_{\theta, s}=0\right)$. Conservation of species at the interface is given by the following expressions:

$$
\text { Fuel: } m_{\theta}^{\prime \prime} Y_{f, s}+\rho_{s} Y_{f, s} \mathrm{~V}_{r, f, s}=m_{\theta}^{\prime \prime}
$$

$$
\text { For other species: } m_{\theta}^{\prime \prime} Y_{i, s}+\rho_{s} Y_{i, s} \mathrm{~V}_{r, i, s}=0
$$

In Eqs. (3) and (4), $m_{\theta}^{\prime \prime}$ represents the local fuel mass flow rate, $\rho$ is the density, $Y$ is the mass fraction, and $V_{r}$ represents the diffusion velocity. The subscripts $f, s$, and $i$, represent fuel, particle surface, and any other species, respectively. The diffusion velocities, which depend upon the concentration and temperature gradients for all $N$ species, are solved according to the method presented by Pope and Gogos [26]. Conservation of energy at the interface, which represents a balance between the heat conducted from ambient to the droplet surface and the heat required for phase change, is given by

$$
m_{\theta}^{\prime \prime} Y_{f, s} L_{f}=\left.k_{s} \frac{d T}{d r}\right|_{s}
$$

In Eq. (5), $L_{f}$ is the latent heat of vaporization of fuel calculated at the interface temperature and $k_{s}$ is the thermal conductivity of the mixture at interface. The interface mass fraction of ethanol is obtained using Clausius-Clapeyron equation. A global single-step reaction for ethanol oxidation is used to model finite rate reaction chemistry. The reaction is given by

$$
\mathrm{C}_{2} \mathrm{H}_{5} \mathrm{OH}+3\left(\mathrm{O}_{2}+3.76 \mathrm{~N}_{2}\right) \rightarrow 2 \mathrm{CO}_{2}+3 \mathrm{H}_{2} \mathrm{O}+11.28 \mathrm{~N}_{2}
$$

The molar based reaction rate $(\overline{\dot{\omega}})$ for the above ethanol-air oxidation is taken from Dubey et al. [18] as

$$
\overline{\dot{\omega}}=1.55 \times 10^{10} \exp \left(\frac{-1.256 \times 10^{8}}{8314.3 \times T}\right)\left[\mathrm{C}_{2} \mathrm{H}_{5} \mathrm{OH}\right]^{0.15}\left[\mathrm{O}_{2}\right]^{1.6} \frac{\mathrm{kmol}}{\mathrm{m}^{3} \mathrm{~s}}
$$

The mass based reaction rate of any species is obtained by multiplying the molar based reaction rate by the molecular weight and stoichiometric coefficient of that species. A domain extent in radial direction of $r_{\infty}=15$ times the particle radius is found to be domain independent. A nonuniform grid, with fine meshes near the particle interface, with 54,300 volumes is found to give gridindependent solution. The discretized equations are solved using the Alternating Direction Implicit method with the Tri-Diagonal Matrix Algorithm. Iterations are performed within each time step until desired convergence, till a given low tolerance value around $10^{-4}$, is achieved. The implicit time marching scheme with a time step value of $0.0001 \mathrm{~s}$ is used. By marching around 100,000 time steps, a converged steady-state solution is obtained for all the cases. All the computations have been carried out on Intel Xeon processor based workstations. 


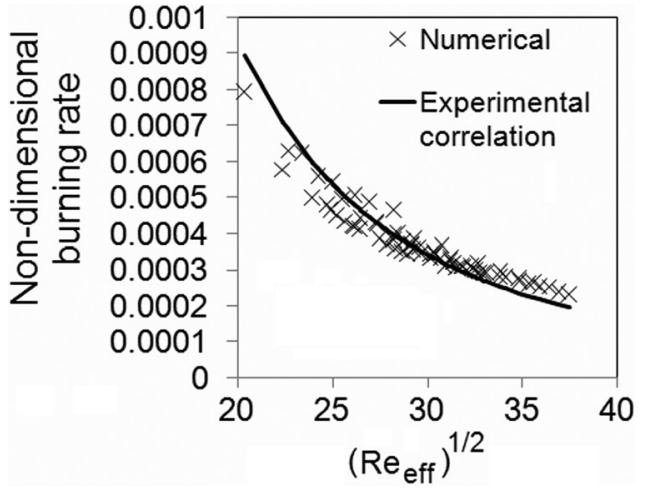

Fig. 2 Variation of nondimensional mass burning rate as a function of square root of effective Reynolds number; symbols show the numerical prediction and solid line shows the experimental correlation reported in Parag and Raghavan [7]

\section{Validation}

Parag and Raghavan [7] have reported steady burning rates of ethanol spheres using porous sphere experiments for different sphere diameters and air velocities at standard atmospheric conditions. These experimental cases have been simulated using the numerical model. After reaching the steady state, the fuel burning rate in $\mathrm{kg} / \mathrm{s}$ has been made nondimensional using the procedure reported in Parag and Raghavan [7], given as follows

$$
\dot{m}^{*}=\frac{\dot{m}}{m_{s p h}} \frac{d}{u_{\infty}}
$$

In Eq. (7), $u_{\infty}$ is the free stream air velocity in $\mathrm{m} / \mathrm{s}, d$ is the sphere diameter, $\dot{m}$ is the mass burning rate in $\mathrm{kg} / \mathrm{s}$, and $m_{\mathrm{sph}}$ is the mass of the fuel particle with radius $r$, given by (4/3) $\pi r^{3}$. The superscript $*$ indicates the dimensionless quantity. Another parameter called effective Reynolds number $\mathrm{Re}_{\text {eff }}$ has been defined to take into account the effects of natural and forced convection [7]

$$
\mathrm{Re}_{\mathrm{eff}}=\frac{u_{\infty} d}{\nu_{\infty}}+\sqrt{\frac{g \beta \Delta T d^{3}}{\nu_{\infty}^{2}}}
$$

Table 1 Composition of oxidizer for different $\phi$ and temperature values

\begin{tabular}{lccc}
\hline \hline Mass fractions & $\phi=0.25$ & $\phi=0.5$ & $\phi=0.75$ \\
\hline $\mathrm{O}_{2}$ & 0.170 & 0.110 & 0.054 \\
$\mathrm{H}_{2} \mathrm{O}$ & 0.032 & 0.062 & 0.091 \\
$\mathrm{CO}_{2}$ & 0.052 & 0.101 & 0.148 \\
$\mathrm{~N}_{2}$ & 0.746 & 0.726 & 0.708 \\
\hline
\end{tabular}

In Eq. (8), $g, \nu_{\infty}, \beta$, and $\Delta T$ represents acceleration due to gravity, free stream kinematic viscosity, coefficient of thermal expansion, and change in temperature, respectively. Figure 2 shows the comparison between the numerically predicted nondimensional mass burning rates against the experimental results as a function of effective Reynolds number, defined by Eq. (8).

The experimental correlation as reported in Parag and Raghavan [7] is given by $\dot{m}^{*}=1.68 /\left(\mathrm{Re}_{\mathrm{eff}}\right)^{1.25}$. There is a slight underprediction in low effective Re cases and slight overprediction in higher effective Re cases. However, for square root of effective $\mathrm{Re}$ in the range of approximately $23-36$, the comparison is quite good (within 10\%). The reasons for the slight differences between the numerical and experimental results are mainly due to neglecting few of the important minor species such as $\mathrm{CO}$ and $\mathrm{OH}$ and some uncertainties in the experiments. This quantitative validation shows that the quasi-steady numerical model, with the global single-step reaction finite rate kinetics and optically thin radiation submodels, is able to predict the ethanol burning rate as measured in experiments and can be further employed to predict the burning rates in a spray environment.

\section{Results and Discussions}

As mentioned before, a spray environment is simulated using an ambient having high temperature and products of combustion present in the oxidizer stream. The oxidizer stream has hot combustion products obtained from the combustion of a lean ethanol-air mixture with equivalence ratio $(\phi)$ values of $0.25,0.5$, and 0.75 . From equilibrium approach, for combustion taking place at atmospheric pressure, the products of combustion (consisting of $\mathrm{CO}_{2}, \mathrm{H}_{2} \mathrm{O}, \mathrm{N}_{2}$, and $\mathrm{O}_{2}$ ) are calculated at four different temperatures: 600,800 , 1000 , and $1200 \mathrm{~K}$. Since the maximum temperature considered in

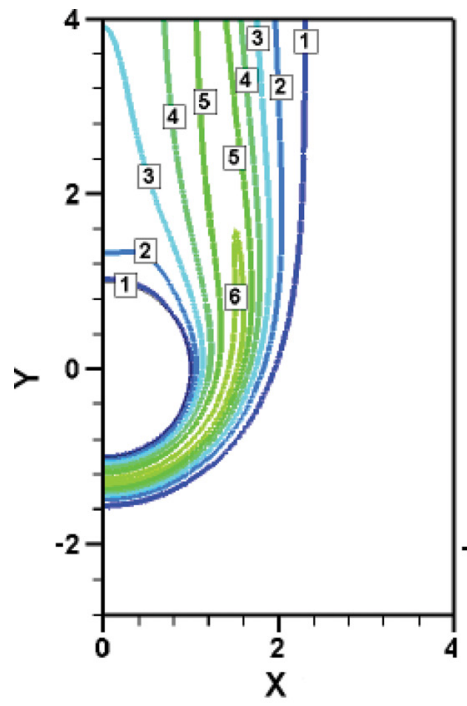

(a) $\mathrm{T}_{\infty}=300 \mathrm{~K}$

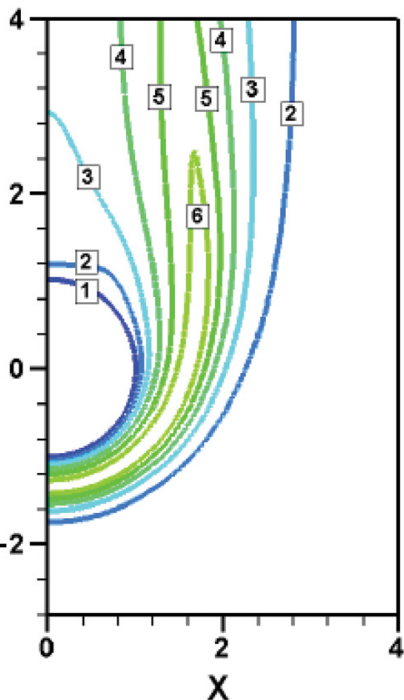

(b) $\mathbf{T}_{\infty}=600 \mathrm{~K}$

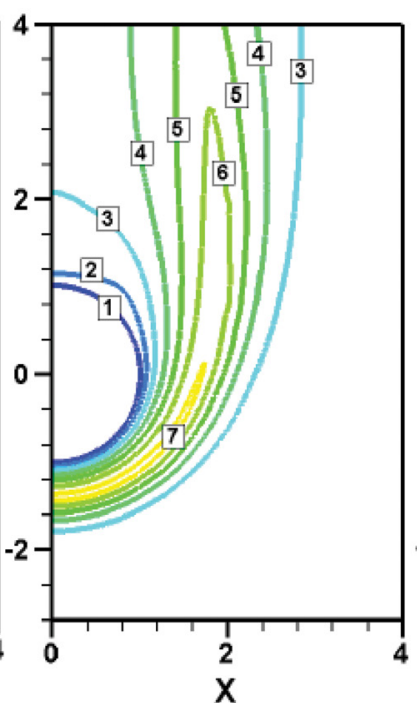

(c) $\mathrm{T}_{\infty}=800 \mathrm{~K}$

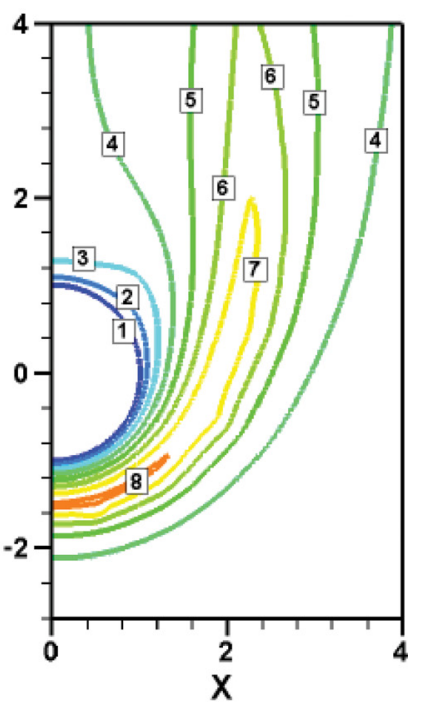

(d) $\mathrm{T}_{\infty}=1200 \mathrm{~K}$

$1-400 \mathrm{~K} \quad 2-700 \mathrm{~K} \quad 3-1000 \mathrm{~K} \quad 4-1300 \mathrm{~K} \quad 5-1600 \mathrm{~K} \quad 6-1900 \mathrm{~K} \quad 7-2200 \mathrm{~K} \quad 8-2500 \mathrm{~K}$

Fig. 3 Temperature contours in the region near the sphere for different ambient temperature cases; oxidizer stream is standard air with oxygen mass fraction of 0.232 


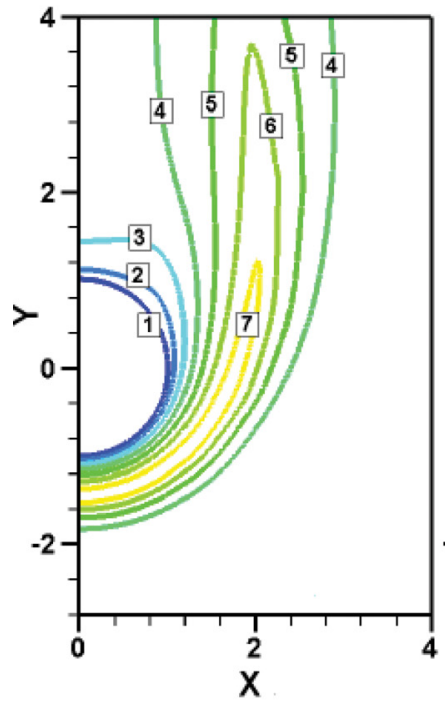

(a) $\Phi=0$

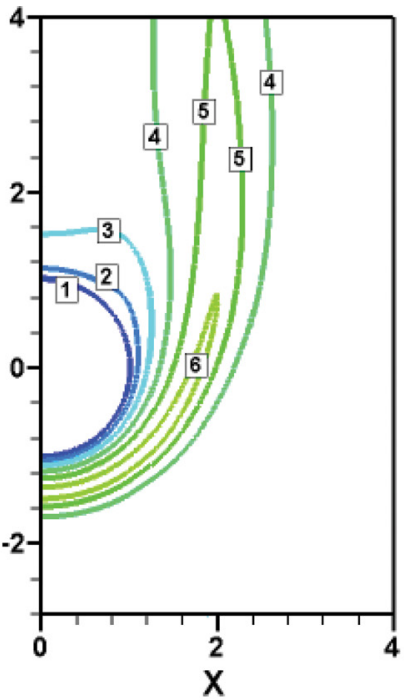

(b) $\Phi=0.25$

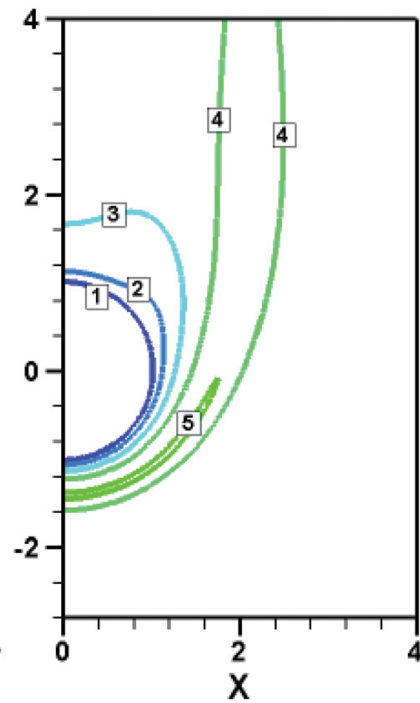

(c) $\Phi=0.50$

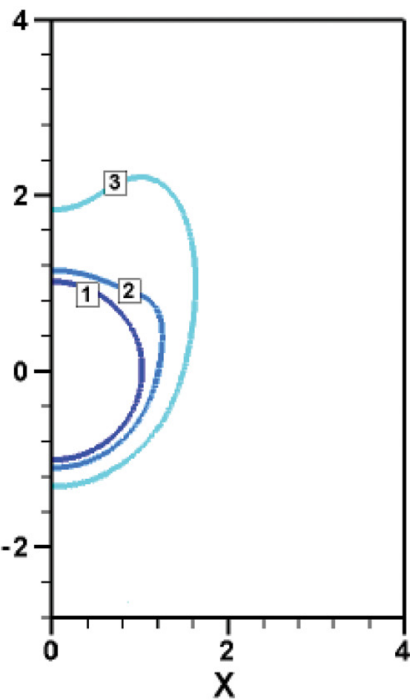

(d) $\Phi=0.75$

$1-400 \mathrm{~K} \quad 2-700 \mathrm{~K} \quad 3-1000 \mathrm{~K} \quad 4-1300 \mathrm{~K} \quad 5-1600 \mathrm{~K} \quad 6-1900 \mathrm{~K} \quad 7-2200 \mathrm{~K} \quad 8-2500 \mathrm{~K}$

Fig. 4 Temperature contours in the region near the sphere for different $\phi$ values at an ambient temperature of $1000 \mathrm{~K}$

this study is $1200 \mathrm{~K}$, only an insignificant dissociation of $\mathrm{CO}_{2}$ and $\mathrm{H}_{2} \mathrm{O}$ occurs. Therefore, the composition is dependent only on $\phi$ values and is shown in Table 1. It is seen that as $\phi$ increases the amount of oxygen in the oxidizer stream decreases. For these simulations, the particle diameter is fixed as $10 \mathrm{~mm}$ and the oxidizer velocity is fixed as $0.44 \mathrm{~m} / \mathrm{s}$, so that only the thermal and chemical effects on evaporation and burning characteristics can be studied.

Numerical simulations have been carried out for each equivalence ratio value for four ambient temperature cases. For comparison sake, simulations with standard air (as in the validation) are performed for higher ambient temperatures of from 600 to $1200 \mathrm{~K}$. Figure 3 shows the temperature contours in the region near to the particle surface for a ethanol particle burning under a pure air stream at different ambient temperatures. As the temperature increases, the maximum temperature of the flame enveloping the sphere also increases due to increased rate of evaporation and higher reaction rates. The high temperature flame zone moves away from the particle surface due to increased blowing velocity from the surface.

On the other hand, when the ambient temperature is held constant at $1000 \mathrm{~K}$ and when the $\phi$ values are changed, the maximum temperature in the domain decreases with increasing $\phi$ value. For the same particle diameter and free stream velocity, Fig. 4 shows the temperature contours for different $\phi$ values at an ambient temperature of $1000 \mathrm{~K}$. The value of $\phi$ is set to zero to represent pure air case. As $\phi$ increases, the availability of oxygen in the oxidizer decreases and the mixture of evaporated ethanol and oxygen becomes oxygen-lean (Table 1 ). When $\phi$ is increased to 0.75 , the flame around the particle extinguishes (maximum temperature around $1200 \mathrm{~K}$ ) and only evaporation of the fuel occurs. This shows even at an ambient temperature of as high as $1000 \mathrm{~K}$, the reduction in oxygen (mass fraction of 0.054 ) has been a dominant effect to cause flame extinction.

However, for the same case $(\phi=0.75)$, when the ambient temperature is increased to $1200 \mathrm{~K}$, a flame is observed around the particle with a maximum temperature of $1803 \mathrm{~K}$. The variation of maximum temperatures around the particle for different values of $\phi$ and ambient temperatures is shown in Fig. 5(a). Even at very low mass fraction of oxygen as in $\phi=0.75$ case (Table 1 ), the particle burns when the ambient temperature is as high as $1200 \mathrm{~K}$. This indicates that $1200 \mathrm{~K}$ is above the auto-ignition temperature for an oxygen-lean ethanol-air mixture formed in this scenario. This also indicates the higher volatility and reactivity of ethanol as compared to fuels such as n-heptane or kerosene. Figure 5(b) shows the variation of burning rate constant in $\mathrm{mm}^{2} / \mathrm{s}$ for different equivalence ratios and ambient temperatures. A decreasing trend in the burning
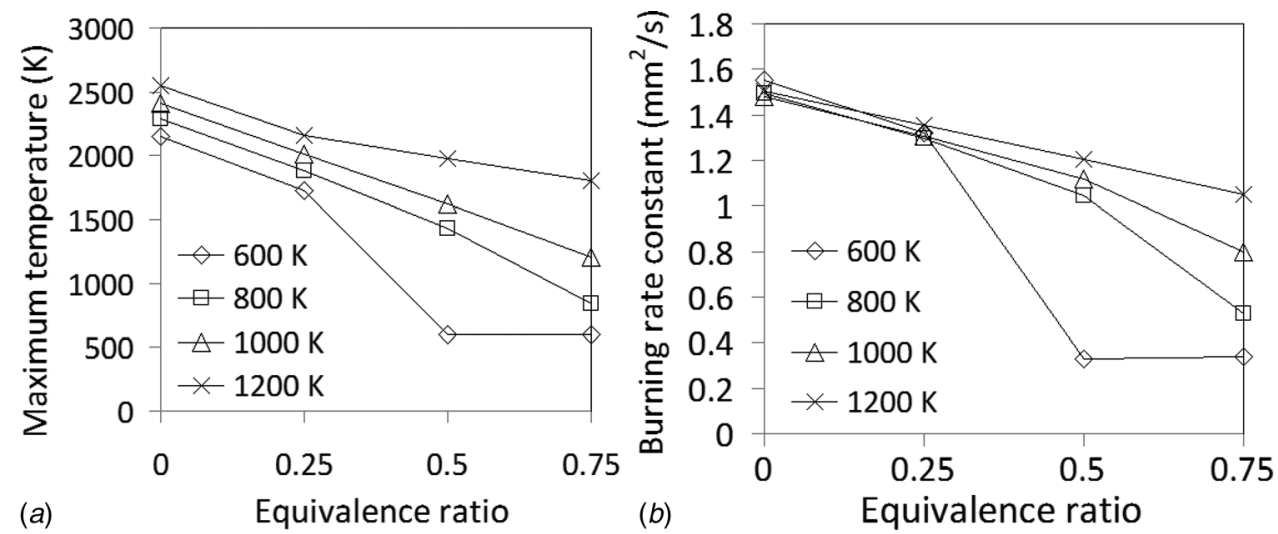

Fig. 5 Variation of maximum temperature around the particle (a) and the burning rate constant (b) as a function of equivalence ratio and ambient temperatures 


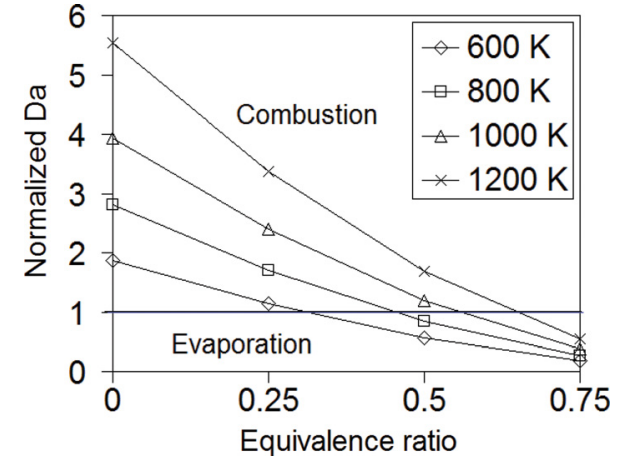

Fig. 6 Variation of normalized Damköhler number as a function of equivalence ratio and ambient temperatures

rate constant is observed with an increasing value of $\phi$. Ambient temperature has an insignificant effect on the burning rate constant for pure air and $\phi=0.25$ cases. This is consistent with the observation by Raghavan et al. [12] in their study with methanol particles. However, when $\phi$ is increased to 0.5 and furthermore, burning rate constant varies based on the ambient temperature. As the oxygen in the oxidizer stream decreases with increasing values of $\phi$, burning occurs only at high ambient temperatures. Especially for $600 \mathrm{~K}$ case, only evaporation occurs for $\phi$ value equal to or greater than 0.5 as seen from Figs. 5( $a)$ and 5(b).

Damköhler number (Da) is the ratio of characteristic flow (or residence) time to chemical reaction time. Characteristic flow time is given as the ratio of particle radius $(R)$ and air velocity $\left(U_{\infty}\right),\left(\tau_{\text {flow }}=R / U_{\infty}\right)$ and is constant, since $R$ and $U_{\infty}$ values are fixed. Chemical reaction time is estimated as the ratio of fuel vapor density $\left(\rho_{F}\right)$, calculated at a mean temperature between the ambient and flame temperatures, to mass based reaction rate $(\dot{\omega})$, $\left(\tau_{\text {chem }}=\rho_{F} / \dot{\omega}\right)$. For a global single-step reaction, the reaction rate can be estimated using Eq. (6) and converted to mass based value by multiplying it with the molar mass of ethanol. By expressing the concentrations of fuel and oxygen as the respective ratios of the density to the molecular mass, the Da can be calculated following Pope and Gogos [11], as follows

$$
\begin{aligned}
\mathrm{Da}= & \frac{R}{U_{\infty}} 1.55 \times 10^{10} \exp \left(\frac{-1.256 \times 10^{8}}{8314.3 \times T_{\max }}\right)\left(\frac{Y_{f}}{M_{f}}\right)^{-0.85} \\
& \times\left(\frac{Y_{O}}{M_{O}}\right)^{1.6} \rho^{0.75} M_{f}
\end{aligned}
$$

In Eq. (9), $Y_{O}$ is the mass fraction of oxygen, $\rho$ is the density of mixture, and $T_{\max }$ is the flame temperature for ethanol reaction with standard air at different ambient temperatures. Mass fractions of oxygen are taken as appropriate mass fractions of oxygen, corresponding to the $\phi$ values (Table 1). The Damköhler number is then normalized by dividing it with a reference value of Damköhler number. Reference Damköhler number is calculated for the case of ethanol particle burning in standard air at standard conditions (ambient temperature of $300 \mathrm{~K}$ ) because this case has the highest mass fraction of oxygen and there is an envelope flame present indicating that the flow time is higher than the chemical reaction time.

Figure 6 shows the variation of normalized Da as a function of equivalence ratio. For normalized $\mathrm{Da}$ greater than unity, flow time is greater than chemical reaction time and there would be sufficient time for combustion to take place. For example, for combustion in standard air, as the ambient temperature increases, normalized Da values become much higher than unity indicating high level of reactivity. The region above the horizontal line, where normalized $\mathrm{Da}$ is greater than unity, indicates that combustion is possible in that region. Similarly, below the horizontal line predominantly evaporation alone takes place.

\section{Conclusions}

A quasi-steady numerical model with finite rate chemistry and optically thin radiation submodels is able to predict the burning rates of spherical ethanol particles in a mixed convective environment; the model has been validated against the porous sphere experimental results reported in literature. A spray environment, in which varying temperature and oxygen concentration conditions would prevail, has been simulated by considering equilibrium products of lean ethanol-air combustion at different equivalence ratios and ambient temperatures. Results show that as ambient temperature increases, the maximum flame temperature also increases. When the value of equivalence ratio increases, the oxygen in the oxidizer decreases. As a result, the maximum flame temperature decreases. The burning rate constant decreases with increasing equivalence ratio. In a pure air stream, the ambient temperature does not significantly affect the evaporation constant for ethanol particles. The effect of ambient temperature on burning rate constant is only significant when the value of equivalence ratio is greater than equal to around 0.5 ; the burning rate constant value decreases with decreasing ambient temperature only after sufficient decrease occurs in the oxygen content. The variation of normalized Damköhler number is also presented to show the cases where combustion or pure evaporation occurs. The case for which normalized $\mathrm{Da}$ is greater than unity indicates the possibility of combustion for that case. Similarly, when the normalized Da value is less than unity, predominantly evaporation alone takes place.

\section{References}

[1] Gajdeczko, B. F., Luff, J., Dryer, F. L., and Lavid, M., 2000, "Laser Ignition of Liquid Oxygen/Ethanol Propellants," Twenty-Eighth Symposium (International) on Combustion: Abstracts of Work in Progress Poster Presentations (No. 2-B20), The Combustion Institute, Pittsburgh, PA, pp. 244.

[2] Kumagai, S., Sakai, T., and Okajima, S., 1971, "Combustion of Free Fuel Droplets in a Freely Falling Chamber," Proc. Combust. Inst., 13(1), pp. 779785.

[3] Gollahalli, S. R., and Brzustowski, T. A., 1973, "Experimental Studies on Flame Structure in the Wake Flame of a Burning Droplet," Proc. Combust. Inst., 14(1), pp. 1333-1344.

[4] Okajima, S., and Kumagai, S., 1982, "Experimental Studies on Combustion of Fuel Droplets in a Flowing Air Under Zero and High-Gravity Conditions," Proc. Combust. Inst., 19(1), pp. 1021-1027.

[5] Hara, H., and Kumagai, S., 1994, "The Effect of Initial Diameter on Free Droplet Combustion With Spherical Flames," Proc. Combust. Inst., 25(1), pp. 423-430.

[6] Yozgatligil, A., Park, S. H., Choi, M. Y., Kazakov, A., and Dryer, F. L., 2007, "Influence of Oxygen Concentration on the Sooting Behavior of Ethanol Droplet Flames in Microgravity Conditions," Proc. Combust. Inst., 31(2), pp. 2165-2173.

[7] Parag S., and Raghavan, V., 2009, "Experimental Investigation of Burning Rates of Pure Ethanol and Ethanol Blended Fuels," Combust. Flame, 156(5), pp. 997-1005.

[8] Hallett, W. L. H., and Beauchamp-Kiss, S., 2010, "Evaporation of Single Droplets of Ethanol-Fuel Oil Mixtures," Fuel, 89(9), pp. 2496-2504.

[9] Balakrishnan, P., Sundararajan, T., and Natarajan, R., 2001, "Combustion of a Fuel Droplet in a Mixed Convective Environment," Combust. Sci. Technol., 163(1), pp. 77-106.

[10] Mukhopadhyay, A., and Sanyal, D., 2005, "A Semi-Analytical Model for Evaporating Fuel Droplets," ASME J. Heat Transfer, 127(2), pp. 199-203.

[11] Pope, D. N., and Gogos, G., 2005, "Numerical Simulation of Fuel Drople Extinction Due to Forced Convection," J. Combust. Flame, 142, pp. 89-106.

[12] Raghavan, V., Babu, V., Sundararajan, T., and Natarajan, R., 2005, "Flame Shapes and Burning Rates of Spherical Fuel Particles in a Mixed Convective Environment," Int. J. Heat Mass Transfer, 48, pp. 5354-5370.

[13] Egolfopoulos, F. N., Du, D. X., and Law, C. K., 1992, "A Study on Ethanol Oxidation Kinetics in Laminar Premixed Flames, Flow Reactors, and Shock Tubes," Proc. Combust. Inst., 24, pp. 833-841.

[14] Li, J., Kazakov, A., and Dryer, F. L., 2001, "Ethanol Pyrolysis Experiments in a Variable Pressure Flow Reactor," Int. J. Chem. Kinet., 133, pp. 859-867.

[15] Marinov, N. M., 1999, "A Detailed Chemical Kinetic Model for High Temperature Ethanol Oxidation,” Int. J. Chem. Kinet., 31, pp. 183-220.

[16] Norton, T. S., and Dryer, F. L., 1992, "An Experimental and Modeling Study of Ethanol Oxidation Kinetics in an Atmospheric Pressure Flow Reactor," Int. J. Chem. Kinet., 24, pp. 319-344.

[17] Kazakov, A., Conley, J., and Dryer, F. L., 2003, "Detailed Modeling of Isolated Ethanol Droplet Combustion Under Microgravity Conditions," Combust. Flame, 134(4), pp. 301-314.

[18] Dubey, R., Bhadraiah, K., and Raghavan, V., 2011, "On the Estimation and Validation of Global Single-Step Kinetics Parameters of Ethanol-Air 
Oxidation Using Diffusion Flame Extinction Data," Combust. Sci. Technol., 183(1), pp. 43-50

[19] Harpole, G. M., 1981, "Droplet Evaporation in High Temperature Environments," ASME J. Heat Transfer, 103(1), pp. 86-91.

[20] Renksizbulut, M., and Yuen, M. C., 1983, "Experimental Study of Droplet Evaporation in a High-Temperature Air Stream," ASME J. Heat Transfer, 105(2), pp. 384-388.

[21] Renksizbulut, M., and Yuen, M. C., 1983, "Numerical Study of Droplet Evaporation in a High-Temperature Stream," ASME J. Heat Transfer, 105(2), pp. 389397.

[22] Szekely, G. A., Jr., and Faeth, G. M., 1983, "Effects of Envelope Flames on Drop Gasification Rates in Turbulent Diffusion Flames," Combust. Flame, 49, pp. 255-259.
[23] Shinji, N., Daisuke, S., Toshikazu, K., Yoshiaki, N., and Tomoya, F., 2011, "Combustion Behaviors of Isolated $n$-Decane and Ethanol Droplets in Carbon Dioxide-Rich Ambience Under Microgravity," Proc. Combust. Inst. 33(2), pp. 2031-2038.

[24] Jin, Y., and Shaw, B. D., 2010, "Computational Modeling of n-Heptane Droplet Combustion in Air-Diluent Environments Under Reduced-Gravity," Int. J. Heat Mass Transfer, 53(25-26), pp. 5782-5791.

[25] Barlow, R. S., Karpetis, A. N., Frank, J. H., and Chen, J. Y., 2001, "Scalar Profiles and No Formation in Laminar Opposed-Flow Partially Pre-Mixed Methane/Air Flames," Combust. Flames, 127(3), pp. 2102-2118.

[26] Pope, D. N., and Gogos, G., 2005, "A New Multi-Component Diffusion Formulation for the Finite Volume Method: Application to Convective Droplet Combustion," Numer. Heat Transfer Part B, 48(3), p. 213. 